\title{
Agronomic
} Journal

\section{BIOAGENTES NA SUPRESSÃO DA VASSOURA-DE-BRUXA E PROMOÇ̃̃O DE CRESCIMENTO NA CULTURA DO CACAUEIRO}

\section{BIOAGENTS IN THE SUPPRESSION OF WITCHES' BROOM AND PROMOTING GROWTH IN CACAUEIRO CULTURE}

Bárbara de Carvalho Moreira ${ }^{1}$; Mikaelle Conceição da Silva ${ }^{2}$; Lucas Marquezan Nascimento3; Marta Cristina Corsi de Filippi4; Fábio José Gonçalves" ${ }^{5}$ Alan Carlos Alves de Souza6*

${ }^{1}$ Engenheira Agrônoma. Centro Universitário de Anápolis - UniEVANGÉLICA. barbaramooreira@hotmail.com.

2Engenheira Agrônoma. Centro Universitário de Anápolis - UniEVANGÉLICA. mika.elly10@hotmail.com.

3Engenheiro Agrônomo. Centro Universitário de Anápolis - UniEVANGÉLICA, curso de Agronomia.mznlucas@outlook.com.

4 Engenheira Agrônoma. Embrapa Arroz e Feijão. cristina.filippi@embrapa.br.

5Biólogo. Laboratório Agrolab.agrolabsementes@gmail.com.

6*Engenheiro Agrônomo. Centro Universitário de Anápolis - UniEVANGÉLICA, curso de Agronomia.

alancarlosagro@gmail.com.Autorcorrespondente.

\section{Info}

Recebido: 02/2021

Publicado: 03/2021

ISSN: 2595-6906

DOI: $10.37951 / 2595-6906.2021 v 5 i 1.6546$

\section{Palavras-Chave:}

Controle biológico; Theobroma cacao;

Moniliophthora perniciosa.

Keywords:

Biologic control; Theobroma cacao;

Moniliophthora perniciosa.

\section{Resumo}

Os grandes problemas na produtividade do cacau é o ataque de várias doenças, sendo a principal a Vassoura-de-bruxa, que é causada pelo fungo Moniliophthora perniciosa. Este trabalho objetiva-se o avaliar a supressão da doença Vassoura-de-bruxa e a avaliação da promoção de crescimento em mudas de cacau com o uso de bioagentes. O experimento foi conduzido em delineamento de blocos inteiramente casualizados, em condições de telado, com os seguintes tratamentos foram: T1testemunha; T2- Trichodermil ${ }^{\circledR}$ (Trichoderma harzianum); T3Bacillus sp.; T4- Burkholderia pyrrocinia. Foi realizado dois tipos de aplicações, uma via foliar e outra via rega, ocorrido de forma simultânea, para a avaliação da severidade da doença, os tratamentos foram aplicados aos 7, 14, 82 e 90 dias após o plantio. Nos resultados obtidos, todos os bioagentes testados foram capazes de a doença, além de apresentarem potencial na promoção de crescimento das plantas.

\section{Abstract}

The major problems in cocoa productivity are the attack of various diseases, the main one being the witches' broom, which is caused by the fungus Moniliophthora perniciosa. This work aims to evaluate the suppression of witches' broom disease and the evaluation of growth promotion in cocoa seedlings with the use of bioagents. The experiment was conducted in a completely randomized block design, under screen conditions, with the following treatments: T1- control; T2- Trichodermil ${ }^{\circledR}$ (Trichoderma harzianum); T3- Bacillus sp.; T4- Burkholderia pyrrocinia. Two types of applications were performed, one leaf and the other irrigation, which occurred simultaneously, to assess the severity of the disease, the treatments were applied at 7, 14, 82 and 90 days after planting. In the results obtained, all the bioagents tested were capable of the disease, in addition to having potential in promoting plant growth.

\section{INTRODUÇÃO}

O cacau (Theobroma cacao) é um fruto característico da região da bacia amazônica, originário de regiões de floresta pluviais da América Tropical, pertencente a regiões de clima quente e úmido. O cacau já era cultivado pelos índios, principalmente os Astecas, no México, e os Maias, na América Central, quando os primeiros colonizadores espanhóis chegaram à América. Hoje em dia ainda pode ser encontrado em estado silvestre, desde o Peru até o México. É de conhecimento que há, predominantemente, três 
variedades de cacaueiro, o Criollo, Forasteiro e o Trinitário (SOUZA, 2019).

O interesse econômico do cacau está na utilização de suas amêndoas para a produção de chocolate e gordura. Para a obtenção do chocolate, além dos fatores genéticos, modificações que ocorrem no seu beneficiamento também são fundamentais para a formação do flavor característico (SILVEIRA, 2016). A importância econômica do cacau no contexto internacional está no fato de ser uma commoditie de participação expressiva no comércio mundial de produtos agrícolas, tanto em importações, quanto exportações (EFRAIM, 2004).

No ano de 2019 a produção girou entorno de 252.540 t e a área plantada de cacau chegou a 620.573 ha-1. No ano de 2020 a produção foi de 238.879 t e, a área plantada de 606.116 ha $^{-1}$. De um ano para o outro, a produção caiu cerca de 13.661 t, e essa queda está relacionada a redução da área cultivada e a ocorrência de diversos problemas nestas áreas, que reduziu em 14.457 ha-1 (IBGE, 2020).

Dentre os grandes problemas que atrapalham a produtividade do cacau é o ataque de patógenos, podendo causar diversas doenças (GRAMACHO et al. citado por PINTO et al., 2014). O cacau é alvo de várias doenças que causam grandes perdas, ocasionando assim grande impacto econômico. Entre estas, a principal é a Vassoura-de-bruxa (Moniliophthora perniciosa) (SANTOS et al., 2010).

A Vassoura-de-bruxa promove diversos sintomas na planta, como: as folhas apresentam tamanho exagerados e deformação; no meristema apical pode ocasionar inchação, superbrotamento e necrose; nas almofadas florais ocorre aglomeração de flores grandes e compridas. Desenvolve, também, vassouras vegetais, da qual ramos emitem flores e brotos deformados. Os frutos menores transformam em frutos inchados e deformados com amadurecimento precoce. Os frutos maiores apresentam mancha dura.
Nas partes doentes e apodrecidas aparecem os basidiocarpos ou cogumelos (GRAMACHO et al., citador por EFRAIM, 2009).

As medidas propostas para o controle da Vassoura-de-bruxa estão incluídas no manejo integrado da doença, utilizando-se métodos de controle químico, genético, cultural e biológico (COSTA et al., 2006). Entre os métodos recomendados para o controle da Vassoura-de-bruxa, o controle biológico vem se destacando, atuando no uso de microrganismos antagônicos a $M$. perniciosa, como fungos do gênero Trichoderma e Rizobactérias Promotoras de Crescimento de Plantas (COSTA; BASTOS, 2000). Segundo Fortes et al. (2007), os fungos do gênero Trichoderma spp. e Rizobactérias Promotoras de Crescimento são promotores de crescimento e indutores de resistência de plantas a doenças e ainda são capazes de atuar como agentes de controle de doenças de várias plantas cultivadas, servindo de opção para o controle biológico. Dentro deste enfoque, este trabalho objetivou-se avaliar a supressão da doença Vassoura-de-bruxa e a avaliação da promoção de crescimento em mudas de cacaueiro com o uso de bioagentes.

\section{MATERIAL E MÉTODOS}

\subsection{Delineamento experimental}

$\mathrm{O}$ ensaio foi conduzido na empresa EMATER - Agência goiana de assistência técnica, extensão rural e pesquisa agropecuária - Estação Experimental de Anápolis - GO. A área possui uma altitude de 1.017 metros, Latitude - 16²0'12.614" S e Longitude 48 53'13.1010', com um clima tropical e estação seca.

$\mathrm{O}$ experimento foi conduzido em delineamento de blocos inteiramente casualizados, em condições de telado, contendo 4 tratamentos e 8 repetições, sendo 4 para avaliação da supressão da doença e 4 para avaliação da promoção de crescimento. Foi utilizado como tratamento um produto comercial a 
base de Trichoderma, com nome Trichodermil ${ }^{\circledR}$ e, rizobactérias, como o Bacillus sp. AGL 21, provenientes da Coleção de Isolados Microbianos do Laboratório Agrolab e, a rizobactéria Burkholderia pyrrocinia BRM 32113, oriunda da Coleção de Microrganismos Multifuncionais da Embrapa Arroz e Feijão.

Os tratamentos foram: T1- testemunha; T2Trichodermil ${ }^{\circledR}$ (Trichoderma harzianum); T3 - Bacillus sp.; T4- B. pyrrocinia. O ensaio foi conduzido a partir de mudas cultivadas em sacos plásticos com substrato Ouro Negro ${ }^{\circledR}$ (esterco de gado e de aves, húmus de minhoca, bokashi e casca de pinus). A cultivar utilizada foi a Forasteiro.

\subsection{Aplicação dos tratamentos}

Os tratamentos foram aplicados em épocas diferentes de acordo com a avaliação realizada. Para a avaliação da severidade da doença, os tratamentos foram aplicados aos 7, 14, 82 e 90 dias após o plantio, sendo realizado dois tipos de aplicações, uma via pulverização foliar e outra via rega, ocorrido de forma simultânea, ou seja, os mesmos tratamentos receberam pulverização foliar e a rega no mesmo dia.

Para a aplicação dos tratamentos compostos por rizobactérias, foram preparadas suspensões bacterianas. As rizobactérias foram multiplicadas em placas de Petri, contendo o meio de cultura BDA, em seguida, as placas foram levadas para uma câmara de crescimento BOD por 48 horas, em aproximadamente $28{ }^{\circ} \mathrm{C}$. Após esse tempo, as placas foram lavadas com água destilada com a ajuda de uma alça de Drigalski, preparando-se a suspensão microbiana (KADO; HESKETT, 1970). A suspensão bacteriana foi padronizada com o auxílio de um espectrofotômetro e ajustada com comprimento de onda de 540 nanômetros e 0,5 de absorbância, obtendo a concentração de $1 \times 10^{8}$ UFC mL-1, conforme Filippi et al. (2011). Para as aplicações via rega das suspensões bacterianas foi adotada a dosagem de $30 \mathrm{~mL}$ por repetição e, para as aplicações via foliar a dosagem adotada foi de 1 L.ha-1, aplicado com o auxílio de um borrifador manual. Para as aplicações do produto Trichodermil ${ }^{\circledR}$ a dosagem utilizada foi de 1 L.ha-1, aplicando via foliar e $30 \mathrm{~mL}$ de calda via rega, conforme recomendações do fabricante. Para a avaliação da promoção de crescimento os tratamentos foram aplicados da mesma forma que a avaliação anterior, via rega e pulverização foliar, porém, realizada somente aos 7 e 14 dias após o plantio.

\subsection{Inoculação do patógeno e avaliação da doença}

O isolado do patógeno $M$. perniciosa, obtido no laboratório da Coleção de Isolados Microbianos do Laboratório Agrolab, foi multiplicado em placas de Petri contendo meio de cultura BDA (Agar, Batata, Dextrose) e incubado em câmara de crescimento BOD, com $28{ }^{\circ} \mathrm{C}$, fotoperíodo de 12 horas, durante 10 dias (COSTA et al., 2010). A inoculação foi realizada aos 90 dias após o plantio, ocorrendo por meio da deposição de disco de micélio do patógeno, de $1 \mathrm{~cm}$ de diâmetro, no meristema apical de cada planta. Em 24 horas antes e após a inoculação do patógeno as plantas foram mantidas a umidade de $100 \%$, em câmara úmida, com o intuito de manter o ambiente favorável para a penetração do fungo. A avaliação da doença foi realizada aos 8 dias após a inoculação, adotando como parâmetro a medição da necrose do meristema apical, com o auxílio de uma régua milimetrada.

\subsection{Avaliação da promoção de crescimento}

Para a promoção de crescimento foram avaliados o comprimento e a biomassa das raízes e da parte aérea das plantas, aos 34 dias após o plantio. As plantas foram medidas com o auxílio de uma régua, medindo-se o tamanho da parte aérea e da parte radicular.

Posteriormente às medições, com o auxílio de uma tesoura, foram separadas a raiz da parte aérea e as plantas foram acondicionadas em sacos de papel e 
levadas para a estufa, onde ficaram por 72 horas a $60^{\circ} \mathrm{C}$ para a secagem. Após a secagem, as plantas foram pesadas em balança de precisão, determinando a biomassa de cada amostra (g).

\subsection{Análise estatística}

Os dados obtidos foram submetidos à análise de variância e teste Tukey, a 5\% de significância. A análise foi realizada com o auxílio do software SPSS, versão 21 .

\section{RESULTADOS E DISCUSSÃO}

\subsection{Promoção de crescimento e biomassa}

Observou-se diferença estatística entre os diferentes tratamentos testados. Os resultados obtidos a partir do comprimento da parte aérea, com plantas tratadas com produto a base do agente biológico Burkholderia pyrrocinia BRM 32113, via rega e via foliar, se destacou em comparação aos demais tratamentos, apresentando aumento de 27,65\% de tamanho em relação a testemunha. Os resultados obtidos através do comprimento da parte radicular, com plantas submetidas ao tratamento via rega e via foliar com o produto comercial Trichodermil ${ }^{\circledR}$, apresentaram resultados positivos quando comparados com a testemunha, havendo aumento de $74,17 \%$ na raiz dessas plantas. (Tabela 1).

Tabela 1- Avaliação de comprimento de raiz e parte aérea da planta, realizadas no trigésimo quarto dia após o plantio de cacau em condições de telado. Teste de Tukey a 5\% de significância. Anápolis - Goiás, 2020.

\begin{tabular}{ccc}
\hline \multirow{2}{*}{ Tratamentos } & \multicolumn{2}{c}{ Comprimento $(\mathrm{cm})$} \\
\cline { 2 - 3 } & Raiz & Parte Aérea \\
\hline Testemunha & $8,75 \mathrm{ab}$ & $12,73 \mathrm{bc}$ \\
Trichodermil $^{\circledR}$ & $15,24 \mathrm{a}$ & $14,50 \mathrm{ab}$ \\
Bacillus sp. $^{8}$ & $7,88 \mathrm{~b}$ & $12,00 \mathrm{c}$ \\
Burkbolderia pyrrocinia & $11,94 \mathrm{ab}$ & $16,25 \mathrm{a}$ \\
\hline CV $(\%)$ & 13,82 & 7,56 \\
\hline
\end{tabular}

*Médias seguidas pelas mesmas letras não diferem entre si pelo teste de Tukey (P>5\%).

Em relação a biomassa da parte aérea, o tratamento composto por plantas tratadas com o bioagente Burkholderia pyrrocinia BRM-32113, se destacou entre os demais, promovendo um aumento de $30,18 \%$ na biomassa em relação com a testemunha. $\mathrm{Na}$ avaliação da biomassa da parte radicular o tratamento contendo plantas tratadas via rega e via pulverização foliar com o produto Trichodermil ${ }^{\circledR}$, a base do fungo Trichoderma, apresentaram resultados significativos, onde observou-se o destaque no aumento de 171,87\% em relação a testemunha (Tabela 2).
As rizobactérias promotoras de crescimento de plantas (BPCP) e os fungo benéficos são microrganismos que habitam na rizosfera e vinculam-se às raízes das plantas e, ainda, conseguem contribuir em uma série de métodos que ocasionam um melhor desenvolvimento das culturas agrícolas (LUVIZOTTO, 2008). Dentro destes métodos associados às BPCP, pode-se mencionar exemplos de mecanismos diretos de promoção de crescimento, como a produção de fitohormônios de crescimento, fixação biológica de nitrogênio (FBN), solubilização e mineralização de nutrientes, como fósforo. (CATTELAN; HARTEL, citado por AHMAD et al., 
2008). Como promotor de crescimento

o Trichoderma tem a capacidade de atuar como bioestimulante no crescimento radicular, favorecendo o crescimento das raízes por meio de fitohormônios e assim, aprimorar a absorção de nutrientes, proporcionando aumento na área radicular da planta, aumento na absorção de nutrientes e desenvolvimento na assimilação de nutrientes e água (HARMAN et al., 2004).

Tabela 2- Avaliação de biomassa de raiz e parte aérea da planta, realizadas no trigésimo sétimo dia após o plantio de cacau em condições de telado. Teste de Tukey a 5\% de significância. Anápolis - Goiás, 2020.

\begin{tabular}{ccc}
\hline & \multicolumn{2}{c}{ Biomassa $(\mathrm{g})$} \\
\cline { 2 - 3 } Tratamentos & Raiz & Parte Aérea \\
\hline Testemunha & $0,032 \mathrm{~b}$ & $0,772 \mathrm{bc}$ \\
Trichodermil $^{\circledR}$ & $0,087 \mathrm{a}$ & $0,915 \mathrm{ab}$ \\
Bacillus sp. & $0,039 \mathrm{ab}$ & $0,610 \mathrm{c}$ \\
Burkholderia pyrrocinia & $0,074 \mathrm{ab}$ & $1,005 \mathrm{a}$ \\
\hline CV $(\%)$ & 10,90 & 14,50 \\
\hline
\end{tabular}

*Médias seguidas pelas mesmas letras não diferem entre si pelo teste de Tukey (P>5\%).

Castro et al. (2020), relataram que a rizobactéria Burkholderia pyrrocinia BRM 32113, como agente biológico na agricultura, foi capaz de estimular o crescimento e desenvolvimento das plantas, e ainda capaz induzir o aumento dos teores de nutrientes foliares em mudas de açaizeiro. Neste mesmo ensaio foi provado que houve acúmulo na biomassa de 95\% para a massa seca total nas mudas inoculadas com a BRM32113. Em outro ensaio, Castro (2018) relatou que em mudas açaizeiro a Burkholderia pyrrocinia BRM 32113 apresentou aceleramento superior no crescimento da parte área e radicular, aumentando a eficiência fotossintética, induzindo o acúmulo de biomassa e de nutrientes foliar e colaborando na diminuição de obtenção de mudas (5 meses) padrão de qualidade para campo.

Resultados obtidos por Baldotto et al. (2010), mostraram que a inoculação com Burkholderia spp., reforçada pela ligação com ácidos húmicos, resultou em maior massa da parte aérea e radicular e com maior capacidade conduzir nutrientes $(\mathrm{N}, 132 \%$;, $131 \%$; $80 \%$ quando comparado com mudas de abacaxizeiro 'Vitória' não inoculadas. Silva et al. (2011), constataram que dezenove isolados de Trichoderma e o produto comercial Trichodermil $^{\circledR}, \quad$ proporcionaram O crescimento da parte aérea e radicular no pepineiro em até $100 \%$, em avaliação ao potencial de diferentes isolados de Trichoderma.

Em um ensaio na cultura do milho, Resende et al. (2004), observaram que o Trichoderma mostrou-se ter maior acumulação de matéria seca do sistema radicular. Em outro experimento Chacón et al. (2007), verificaram que as plantas de tomateiro, inoculadas com T. harzianum, promoveram crescimento significativo na parte área e radicular, no qual as raízes secundárias aumentaram três vezes mais. O autor explicou que essa promoção significativa do crescimento da planta é devido ao desenvolvimento de uma relação simbiótica planta-fungo ou à secreção de fitormônios por $T$. harzianum.

\subsection{Supressão da doença}

Houve diferença estatística entre os tratamentos testados. Em relação a severidade da doença no controle do Moniliophthora perniciosa, os tratamentos compostos por plantas tratadas via rega e pulverização foliar com Burkholderia pyrrocinia BRM 32113, Bacillus sp. AGL 21 e Trichodermil $^{\circledR}$, apresentaram resultados 
positivos em relação a testemunha, apresentando $86,74 \%$; 93,02\% e 94,24\% de supressão da doença, respectivamente (Figura 1$)$.

As rizobactérias apresentam eficiência na supressão contra diversos fitopatógenos, as quais conseguem colonizar plantas de diversas espécies botânicas, podendo, também, atuarem na promoção do crescimento vegetal (KLOEPPER et al., citado por PASCHOLATI et al., 2019). As RPCPs oferecem

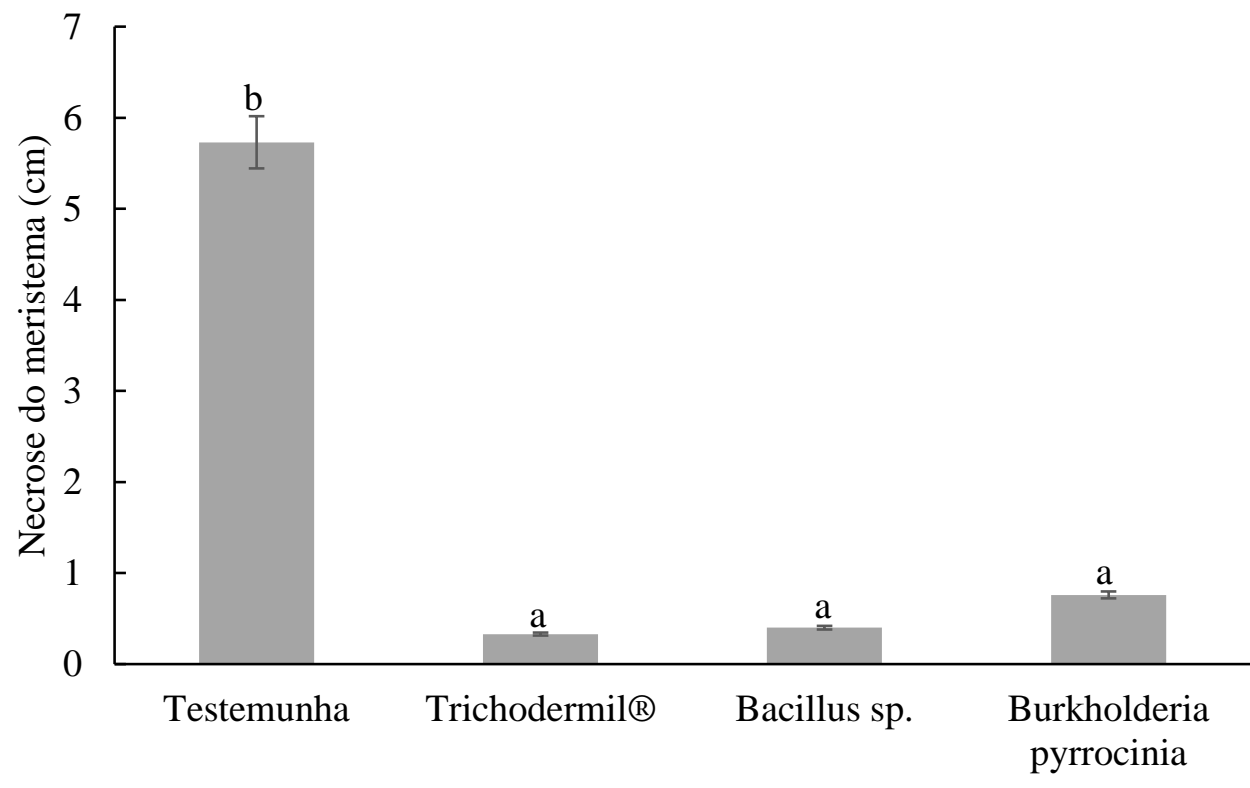

Figura 1- Avaliação de supressão da Vassoura-de-bruxa em plantas de cacaueiro tratadas com bioagentes em condições de telado. Teste de Tukey a 5\% de significância. Anápolis - GO.

O Trichoderma possui algumas espécies que são micoparasitas, eficientes no controle de fungos fitopatogênicos, principalmente os que possuem estruturas de resistências difíceis de serem atacadas por microrganismos. A atuação do microrganismo pode ser através de um mecanismo ou da associação como parasitismo, antibiose e competição (BETTIOL; GHINI, citado por REMUSKA; DALLA PRIA, 2007). As informações sobre o uso de antagonistas para o controle de doenças causadas por fungos fitopatogênicos retrata o Trichoderma spp. como o agente mais favoráveis entre os microrganismos de biocontrole (SILVA et al., citado por REMUSKA; DALLA PRIA, 2007). Fungos do gênero Trichoderma são capazes de produzir enzimas que podem degradar benefícios associados ao controle de doenças de plantas. Esses benefícios podem ser vistos em diferentes culturas. Esses benefícios partem de uma variedade de mecanismos, como o controle biológico por meio da competição com patógenos por nutrientes, resistência induzida a doenças, a produção de antibióticos e outros mecanismos (SOTTERO et al, 2006). 
Trichoderma stromaticum tem eficiência quando diluído em água e pulverizado na plantação de cacau, com competência de inibir a reprodução do fungo da Vassoura-de-bruxa cerca de 57\% na copa do cacaueiro e até 99\% no solo. Resultados obtidos por Adedeji et al. (2008), evidenciaram que na doença da podridão parda do cacaueiro causada por pelo fungo Phytophthora megakarya apresentou redução de incidência em 85\% com a utilização do isolado de Trichoderma.

Em um estudo feito na cultura dos citros em condições de campo, foram testados sete isolados de Bacillus subtilis para controle da doença podridão floral dos citros (Colleototrichum acutatum). Neste teste, Kupper et el. (2003) obseravaram que todos os isolados inibiram o crescimento micelial do patógeno, porém, o Bacillus subtilis ACB-69 mostrou maior eficácia de controle, comparado estatisticamente a um fungicida químico, proporcionando menor porcentagem de flores com sintomas e maior número médio de frutos efetivos. Em outro estudo, Kupper (2009) constatou que no controle da doença da mancha preta (Guignardia citricarpa) dos frutos cítricos, sob condições de laboratório e campo, os isolados de Bacillus subtilis apresentou eficiência na supressão da mancha preta (Guignardia citricarpa) no cítros e da queda prematura de frutos cítricos. Resultados obtidos por Costa et al. (2007), mostraram que tratamento com Bacillus subtilis que apresenta efeito protetor e indutor de resistência, comparado com a testemunha ocasionou a redução da severidade da ferrugem do cafeeiro em mais de 90\%, igualando-se a resultados com tratamentos químicos.

$\mathrm{Na}$ literatura não foram encontrados relatos de resultados em que a bactéria Burkholderia pyrrocinia tenha sido testada no controle do fungo Moniliophthora perniciosa, porém, em uma pesquisa realizada por Castro (2018), constatou que microrganismos do gênero Burkholderia associadas com outras rizobactérias foram capazes de reduzir $26 \%$ a severidade da doença antracnose (Colletotrichum sp.) em mudas de açaizeiro.
Através de análises feitas com espectrometria, Bach (2016) constatou que a Burkholderia sp. gera diferentes diversidades de compostos antifúngicos, verificando ao gênero potencial biotecnológico com possível controle biológico de fungos fitopatogênicos em aplicações farmacêuticas e agronômicas.

\section{CONCLUSÃO}

Os resultados obtidos com os bioagentes Bacillus sp. AGL 21, Burkholderia pyrrocinia BRM 32113 e Trichoderma, mostraram-se eficientes no controle da Moniliophthora perniciosa na cultura do cacaueiro, além de apresentar potencial na promoção de crescimento nas plantas, para o crescimento da biomassa e também no comprimento da parte área e das raízes. Maiores estudos precisam ser realizados para o aprofundamento do conhecimento sobre o efeito destes bioagentes na cultura do cacaueiro. O uso destes microrganismos pode ser é uma alternativa para o manejo nutricional de plantas e para o manejo integrado da vassoura-de-bruxa do cacaueiro, tendo em vista sistemas agrícolas mais sustentáveis, contribuindo para o aumento da produtividade.

\section{REFERÊNCIAS}

ADEDEJI, A. R., ODEBODE, A. C., AGBENIYI, S. O. Bioassay of five Trichoderma strains against Phytophthora megakarya (Cacao pod-rot) in Nigeria. Scientific Research and Essays, v. 3, n. 9, p. 390-394, 2008.

AHMAD, F., AHMAD, I., KHAN, M. S. Screening of free-living rhizospheric bacteria for their multiple plant growth promoting activities. Microbiological research, v. 163, n. 2, p. 173-181, 2008.

AMORIM, A. O.; ORLANDELLI, R. C.; PAMPHILE, J. A. Controle de Patógenos do Cacaueiro (Theobroma Cacao L.) por Fungos Endofíticos dos Gêneros Trichoderma e Clonostachys. Revista Uningá Review, v. 34, n. 1, p. 1-10, 2019. 
BACH, E. Utilização de Burkholderia sp. para o controle biológico de fungos fitopatogênicos e identificação de moléculas de seu metabolismo secundário envolvidas nesse processo. 2016. Disponível em: < http://go.microsoft.com /fwlink/p/?LinkId/255141 >. Acesso em: 11/11/2020.

BALDOT'TO, L. E. B., BALDOT'TO, M. A., CANELLAS, L. P., BRESSAN-SMITH, R., OLIVARES, F. L. Promoção do crescimento do abacaxizeiro 'vitória' por ácidos húmicos e Burkholderia spp. durante a aclimatização. Revista Brasileira de Ciência do Solo, v. 34, n. 5, p. 1593 1600, 2010.

CASTRO, G. L. S. de. Rizobactérias promovem crescimento, aliviam os efeitos do déficit hídrico e reduzem antracnose em mudas de açaizeiro. 2018. 126 f. Tese (Doutorado em Agronomia) Universidade Federal Rural da Amazônia, Belém, 2018.

CASTRO, G. L. S.; SANTOS, G. R.; RÊGO, M. C. F.; BATISTA, T. F. V.; SILVA, G. B. Estudos Teóricos- Metodológicos nas Ciências Exatas, Tecnológicas e da Terra 2. Burkholderia pyrrocinia induz acúmulo nutricional e promove crescimento de mudas de açaizeiro Ponta Grossa-PR, cap. 8 pg. 64-68, 2020.

CHACÓN, MR, RODRÍGUEZ GALÁN, O., BENÍTEZ FERNÁNDEZ, CT, SOUSA, S., REY, M., LLOBELL GONZÁLEZ, A., DELGADO JARANA, J. Microscopic and transcriptome analyses of early colonization of tomato roots by "Trichoderma harzianum". International microbiology: official journal of the Spanish Society for Microbiology, vol. 10, n. 1, p. 19-27. 2007.

COSTA, H. S. Rizobactérias promotoras do crescimento de mudas de Theobroma cacao L. Tese (Doutorado em Biotecnologia) - Universidade Federal do Amazonas, Manaus, 2007. 124 p.

COSTA, J. C. B., BASTOS, C. N. Controle biológico da vassoura-de-bruxa. Anais. Reunião de Controle Biológico de Fitopatógenos, p. 45-51, 2000 .

COSTA, J. C. B., BEZERRA, J. L., VELOSO, J. L. M., NIELLA, G. R., BASTOS, C. N. Controle biológico da vassoura-de-bruxa do cacaueiro. Tecnologias Alternativas para $\mathrm{O}$ Controle de Pragas e Doenças. Viçosa-MG, Brazil: EPAMIG, p. 25-47, 2006.
COSTA, J.C.B.; RESENDE, M.L.V.; JÚNIOR, P.M.R.; CAMILO, F.R.; MONTEIRO, C.A.; PEREIRA, R.B. Indução de Resistencia em mudas de cacaueiro contra Moniliophtora perniciosa por produto à base de mananoligossacarídeo fosforilado. Lavras, MG, Brasil, 2010. 10 p.

EFRAIM, P. Contribuição a melhoria de qualidade de produtos de cacau no Brasil, por meio da caracterização de derivados de cultivares resistentes a vassoura-de-bruxa e de sementes danificadas pelo fungo. 2009. 208 p. Tese (doutorado) - Universidade Estadual de Campinas, Faculdade de Engenharia de Alimentos, Campinas, SP.

EFRAIM, P. Estudo para minimizar as perdas de flavonóides durante a fermentação de sementes de cacau para produção de chocolate. Campinas, SP: [s.n.], 2004.

FILIPPI, M. C. C.; SILVA, G. B.; SILVA-LOBO, V. L.; CÔRTES, M. V. C. B.; MORAES, A. J. G.; PRABHU, A. S. Leaf blast (Magnaporthe oryzae) suppression and growth promotion by rhizobacteria on aerobic rice in Brazil. Biological Control, v. 58, n. 2, p. 160-166, 2011.

FORTES, F. D. O., SILVA, A. C. F. D., AALMANÇA, M. A. K., TEDESCO, S. B. Promoção de enraizamento de microestacas de um clone de Eucalyptus sp. por Trichoderma spp. Revista Árvore, v. 31, n. 2, p. 221-228, 2007.

HARMAN, G. E., HOWELL, C. R., VITERBO, A., CHET, I., LORITO, M. Trichoderma speciesopportunistic, avirulent plant symbionts. Nature reviews microbiology, v. 2, n. 1, p. 43-56, 2004.

IBGE. Levantamento Sistemático da Produção Agrícola. Disponível em: <https://www.ibge.gov.br/estatisticas/econom icas/agricultura-e-pecuaria/9201-levantamentosistematico-da-producaoagricola.html? $=\& \mathrm{t}=$ resultado $>$. Acesso em: 10 de mar. de 2020.

KADO, C.I. HESKETT, M.G. Selective media for isolation of agrobacterium, Corynebacterium, Erwinia, Pseudomonas and Xanthomonas. Phytopathology, v. 60, n. 6, p. 969-976, 1970.

KUPPER, K. C. Controle biológico de doenças de flores e frutos jovens de citros. Biocontrole de Doenças de Plantas, p. 289, 2009. 
KUPPER, K. C., GIMENES-FERNANDES, N., GOES, A. D. Controle biológico de Colletotrichum acutatum, agente causal da queda prematura dos frutos cítricos. Fitopatologia brasileira, v. 28, n. 3, p. 251-257, 2003.

LOUZADA, G. A. D. S., CARVALHO, D. D. C., MELLO, S. C. M., LOBO JÚNIOR, M., MARTINS, I., BRAÚNA, L. M. Potencial antagônico de Trichoderma spp. originários de diferentes agroecossistemas contra Sclerotinia sclerotiorum e Fusarium solani. Biota neotropica, v. 9, n. 3, p. 145-149, 2009.

LUVIZOTTO, D. M. Caracterização fisiológica e molecular de Burkholderia spp. associadas às raízes de cana-de-açúcar. Tese de Doutorado. Universidade de São Paulo. 2008.

PASCHOLATI, S. F.; SOUZA, V. H. M.; FILHO, J. A. C. Trichoderma: uso na agricultura. Embrapa SojaLivro científico (ALICE), Brasília- DF, Capitulo $71^{\circ}$ edição, 2019. p. 235-246.

PINTO, D.G.; AGUILAR, M.A.G.; SOUZA, C.A.S.; SILVA, D.M.; SIQUEIRA, P.R.; CAO, J.R. Fotossíntese, crescimento e incidência de insetos-praga em genótipos de cacau pulverizados com silício. - Uberlândia, 2014

REMUSKA, A. C.; DALLA PRIA, M. Efeito de Bacillus thuringiensis e Trichoderma sp. no crescimento de fungos fitopatogênicos. Ponta Grossa, 2007.
SANTOS, M. F. D., COSTA, D. L. D., MATOS, J. C. D. N. D., SILVA, G. B. D., VIEIRA, T. A., LUSTOSA, D. C. Tratamento biológico de sementes de cupuaçu para o controle de fitopatógenos e promoção da germinação. Cadernos de Agroecologia, v. 13, n. 1, 2018.

SANTOS, R. M.; LEMOS, L. S. L.; JUCA, F. F.; DOS SANTOS, M. V. O.; KRUSCHEWSKY, M. C.; GANEM, R. S.; GRAMACHO, K. P. Obtenção de produtos de PCR dos principais fungos causadores de doenças no cacaueiro visando estudos filogeneticos e taxonômicos. 2010.

SOTTERO, A. N.; dos SANTOS FREITAS, S.; de MELO, A. M. T.; TRANI, P. E. Rizobactérias e alface: colonização rizosférica, promoção de crescimento e controle biológico. Revista Brasileira de Ciência do Solo, v. 30, n. 2, p. 225-234, 2006.

SOUZA, C. A. S., CORREAA, F. D. O., MENDONÇA, V., VICHIATO, M., CARVALHO, J. D. Doses de fósforo e zinco no acúmulo de macro e micronutrientes em mudas de cacaueiro. Agrotrópica, 18.2006.

SOUZA, E.C.M. Cacau (Amêndoa) Análise mensal. CONAB. Brasília, 2019. Disponível em $<$ https://www.conab.gov.br/infoagro/analises-do-mercado-agropecuario-eextrativista/analises-do-mercado/historicomensal-de-cacau/item/11899-cacau-analisemensal-julho-2019>. Acesso em 22 de mar. de 2020 . 